\title{
Identifikasi Daerah Longsor Kecamatan Bagelen menggunakan Metode Mikrotremor
}

\section{Gofur Dyah Ayu Gilang Pertiwi ${ }^{1}$ *, Nugroho Budi Wibowo², Denny Darmawan ${ }^{1}$}

\section{${ }^{1}$ Program Studi Fisika, Universitas Negeri Yogyakarta,} Jl. Colombo 1 Yogyakarta 55281

${ }^{2}$ BMKG Stasiun Geofisika Kelas 1 Yogyakarta, Jl. Wates Km.8 Jitengan, Balecatur, Gamping, Sleman, Yogyakarta

* Penulis Penanggungjawab. E-mail: ayugofur@gmail.com

\begin{abstract}
ABSTRAK
Kecamatan Bagelen merupakan wilayah di sisi barat Pegunungan Menoreh yang mengalami tanah longsor akibat adanya perubahan kondisi geologi menjadi material lepas dan terlongsorkan. Penelitian ini bertujuan untuk mengetahui karakteristik daerah longsor di Kecamatan Bagelen berdasarkan persebaran dan pemodelan parameter mikrotremor, yaitu frekuensi predominan, faktor amplifikasi, ketebalan lapisan sedimen, dan indeks kerentanan seismik. Data mikrotremor diolah dengan metode HVSR dan metode Ellipticity Curve. Hasil penelitian menunjukkan bahwa $f_{0}$ daerah longsor adalah $6-8 \mathrm{~Hz}$, nilai $A$ adalah 6-7 Hz, dan nilai $\mathrm{Kg}$ adalah $5 \times 10^{-4}-1,1 \times 10^{-3} \mathrm{~s}^{2} / \mathrm{m}$. Ketiga parameter tersebut berada dalam kategori sedang hingga tinggi serta nilai ketebalan sedimen 20-50 m.
\end{abstract}

Kata Kunci : Tanah Longsor; Mikrotremor; Kecamatan Bagelen 


\begin{abstract}
Bagelen District located in the west of Menoreh Mountain that had landslide caused by deformation. The research aimed to characterize the landslide area in Bagelen District based on microtremor parameters: predominant frequency, amplification factor, sediment layer thickness, and seismic vulnerability index. Data in the form of microtremor signals were then processed by HVSR and ellipticity curve method. The results of the research showed that the value of $f 0$ ranged from 6 to $8 \mathrm{~Hz}$, the value of $A$ ranged from 6 to 7, the value of $H$ ranged from 20 to $50 \mathrm{~m}$ and the value of $\mathrm{Kg}$ ranged from $5 \times 10^{-4}-1,1 \times 10^{-3} \mathrm{~s}^{2} / \mathrm{m}$. The parameter was on medium and high categories with 20 - $50 \mathrm{~m}$ sediment layer thickness.
\end{abstract}

Keywords: Landslide; Microtremor; Bagelen District

\section{Pendahuluan}

Kecamatan Bagelen merupakan wilayah berupa dataran rendah hingga tinggi yang sebagian wilayahnya masuk dalam gugusan lereng Pegunungan Menoreh. Secara geologis, dataran tinggi di Kecamatan Bagelen berada pada formasi geologi Kebobutak, Andesit dan Dasit serta memiliki sejarah geologi gunung api purba, yaitu Gunung Ijo. Karakteristik geologi di dataran tinggi Kecamatan Bagelen didominasi material kompak dan keras seperti breksi, andesit, dan batuan vulkanik.

Kecamatan Bagelen merupakan wilayah dengan ketinggian $0-325$ mdpl dengan memiliki kemiringan lereng berkisar antara $1-45 \%$ serta memiliki iklim tropika basah yang bercurah hujan 2000-3000mm/tahun[1].

Kondisi wilayah dengan kemiringan lereng yang curam serta banyak vegetasi yang tumbuh di sekitar lereng menyebabkan terjadinya proses pelapukan. Proses pelapukan tersebut dapat menyebabkan terpecahnya material yang kompak menjadi material lepas dan mudah terlongsorkan. Hal ini yang menyebabkan wilayah di Kecamatan Bagelen mengalami kejadian tanah longsor yang cukup tinggi. Berdasarkan laporan BPS Purworejo tahun 2016, 70\% wilayah di Kecamatan Bagelen berada pada tingkat kerawanan longsor sedang hingga tinggi [2].

Penelitian mengenai kejadian tanah longsor di Kecamatan Bagelen pernah dilakukan oleh Atmoko [3] dan Mey [4]. Kedua penelitian tersebut sebatas mengetahui persebaran dan upaya mitigasi 
dengan GIS (Geographic Information system). Belum ada penelitian yang digunakan untuk mengetahui karakteristik geologi atau struktur lapisan bawah permukaan di Kecamatan Bagelen, dimana karakteristik geologi setempat tersebut dapat menunjukkan bagaimana material- material dapat terlongsorkan.

Metode mikrotremor merupakan kajian yang dapat dilakukan untuk mengetahui karakteristik geologi suatu wilayah. Melalui analisis HVSR (horizontal to vertical spectral ratio) maka dapat diketahui nilai frekuensi predominan yang menyatakan susunan material yang mendominasi suatu wilayah dan nilai faktor amplifikasi yang menyatakan perbesaran gelombang yang dialami suatu wilayah. Kondisi lapisan bawah permukaan dapat diketahui melalui pengolahan inversi dengan metode Ellipticity Curve. Oleh karena itu, penelitian dengan metode mikrotremor dapat digunakan untuk mengkaji karakteristik daerah yang terjadi longsor, seperti yang dilakukan Warnana [5] untuk mengetahui efek lokal dari daerah longsor di Kabupaten Jember, oleh Shaleha [6] untuk mengidentifikasi struktur lapisan tanah daerah rawan longsor di Kecamatan Banyubiru, Kabupaten Semarang dan oleh Ramadhan [7] untuk memetakan daerah rawan longsor di Kecamatan Batur, Kabupaten Banjarnegara.

\section{Metode Penelitian}

Pengambilan data dilakukan pada 32 titik penelitian dengan spasi $1 \mathrm{Km}$ menggunakan satu set alat Digital Portable Seismpgraph merk Taide tipe TDL -3035. Wilayah penelitian dibatasi pada koordinat $7^{\circ} 46^{\prime} 40,58 ”-7^{\circ}$ 49'23,99" LS dan $110^{\circ} 1$ '22,65'$110^{\circ} 3$ '33,46', BT yang mencakup 8 desa di Kecamatan Bagelen.

Data mikrotremor yang diperoleh kemudian diolah dengan metode HVSR pada software Geopsy. Hasil pengolahan tersebut berupa kurva $\mathrm{H} / \mathrm{V}$ yang dapat menunjukkan nilai frekuensi predominan dan faktor amplifikasi suatu titik penelitian. Pengolahan selanjutnya adalah dengan melakukan inversi kurva $\mathrm{H} / \mathrm{V}$ dengan metode ellipticity curve pada software Dinver. Pengolahan tersebut menghasilkan ground profile yang menunjukkan nilai kecepatan gelombang geser (Vs) setiap lapisan beserta nilai ketebalan lapisannya.

Analisis karakteristik daerah longsor di Kecamatan Bagelen diketahui melalui pemetaan dan pemodelan parameter- parameter yang telah diperoleh dari analisis, yaitu frekuensi predominan, faktor amplifikasi, indeks kerentanan seismik dan ketebalan sedimen. Titik- 
titik kejadian longsor kemudian dioverlay dalam hasil pemetaan dan pemodelan.

\section{Hasil dan Pembahasan}

Dalam hasil penelitian, terdapat 11 titik longsor yang berada dalam daerah penelitian sepanjang bulan Mei 2017 hingga Februari 2018. Titik -titik longsor tersebut berada di Formasi Kebobutak dan Andesit, serta berada di daerah yang memiliki kemiringan curam.
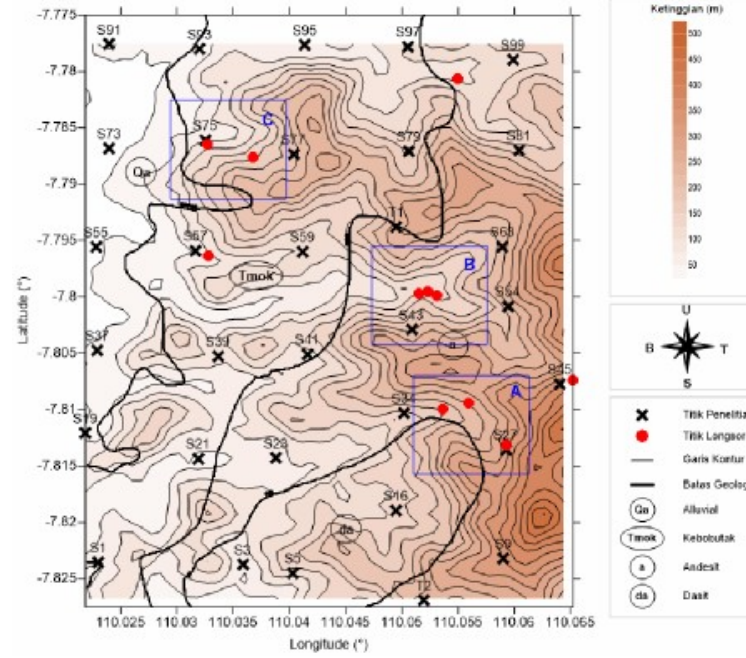

Gambar 1. Peta Penelitian

Identifikasi daerah longsor di Kecamatan Bagelen dibagi menjadi tiga bagian, yaitu bagian A, bagian $\mathrm{B}$, dan bagian $\mathrm{C}$ seperti yang ditunjukkan pada Gambar 1 . Daerah-daerah yang diidentifikasi tersebut dipilih karena mengalami kejadian longsor lebih dari satu kali. Melalui hasil hasil mikrozonasi frekuensi predominan, mikrozonasi dan pemodelan faktor amplifikasi, mikrozonasi indeks kerentanan seismik serta melalui hasil pemodelan kecepatan gelombang geser dan stratigrafi.

Daerah longsor bagian A berada di Desa Hargorojo. Terdapat tiga titik longsor yang berada di dataran tinggi, dimana titik A1 berada di ketinggian 290 m serta titik A2 dan A3 berada di ketinggian $245 \mathrm{~m}$. Tanah longsor yang terjadi pada daerah tersebut merupakan longsor jenis runtuhan (falls) material yang telah lapuk seperti batuan pasir dan batuan lempung. Daerah longsor bagian B merupakan tiga titik longsor yang berdekatan di Desa Sokoagung. Ketiga titik longsor berada di ketinggian $130 \mathrm{~m}$. Tanah longsor yang terjadi di daerah B berupa runtuhan (falls) di sebutah tebing dan badan jalan dengan material berupa lempung dan batuan lempung. Daerah longsor bagian $\mathrm{C}$ merupakan dua titik longsor yang berada di Desa Soko, dimana titik $\mathrm{C} 1$ berada di ketinggian 90 $\mathrm{m}$ dan titik $\mathrm{C} 2$ berada di ketinggian 150 $\mathrm{m}$. Longsor di titik $\mathrm{C} 1$ merupakan longsor translasi, dimana massa tanah ambles pada bidang gelincir sedangkan longsor pada titik C2 merupakan longsor runtuhan (falls) dimana material pada 
pada dinding jurang ambrol dan membuat badan jalan menjadi retak.

\section{Frekuensi Predominan dan}

\section{Ketebalan Lapisan Sedimen}

Berdasarkan hasil mikrozonasi yang ditunjukkan pada Gambar 2, maka dapat diketahui bahwa daerah longsor bagian A dan B memiliki nilai frekuensi predominan yang tinggi, yaitu bernilai $7 \mathrm{~Hz}$ di titik A1, A2, B1 dan $\mathrm{B} 2$ serta bernilai $8 \mathrm{~Hz}$ di titik A3 dan B3. Nilai tersebut diketahui sebagai tanah jenis I yang didominasi oleh batuan keras (hard sandy gravel) sesuai dengan kondisi geologi daerah longsor bagian A dan B yang berada pada Formasi Andesit. Untuk daerah longsor bagian $\mathrm{C}$ yang berada pada Formasi Kebobutak, nilai frekuensi predominan bernilai sedang dan tinggi, dimana bernilai $6 \mathrm{~Hz}$ di titik $\mathrm{C} 2$ dan bernilai $7 \mathrm{~Hz}$ di titik $\mathrm{C}$. Nilai tersebut diketahui sebagai tanah jenis I dan II, yaitu kondisi tanah yang berupa batuan keras (hard sandy gravel), pasir kerikil (sandy gravel), lempung keras (sandy hard clay), dan tanah liat (loam).
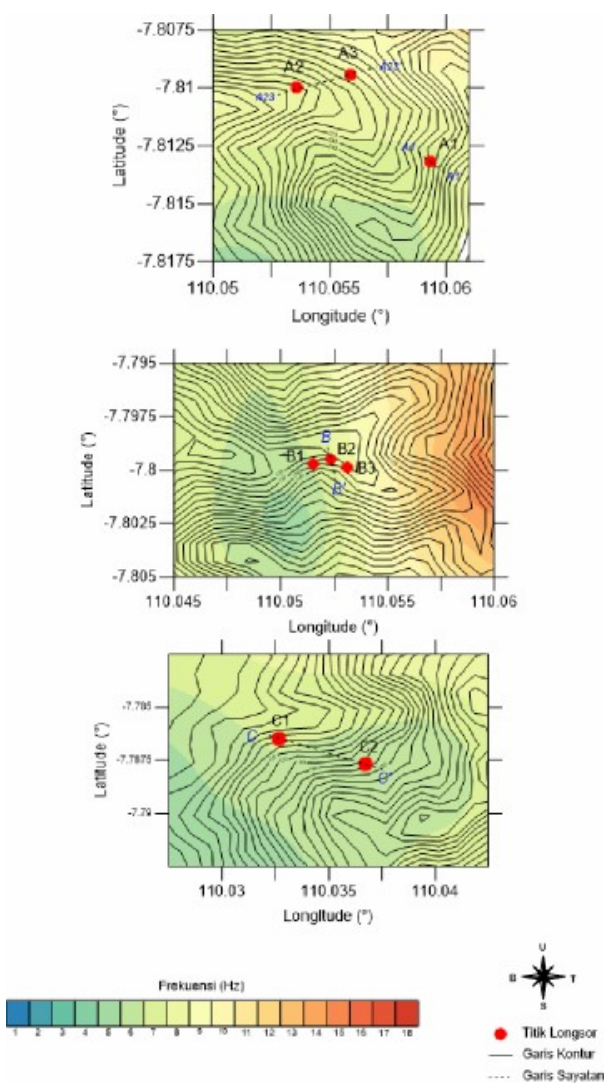

Gambar 2. Mikrozonasi Nilai Frekuensi Predominan

Nilai ketebalan lapisan sedimen diketahui melalui proses pemodelan 3D nilai kecepatan gelombang geser yang diperoleh dari pengolahan ellipticity curve berupa ground profile.

Pengkategorian lapisan didasarkan pada klasifikasi nilai kecepatan gelombang geser $(V \mathrm{~s})$ oleh Badan Standarisasi Nasional ${ }^{[8]}$. Pemodelan yang diperoleh kemudian dilakukan penyayatan (crosssection) pada titik lokasi longsor. 

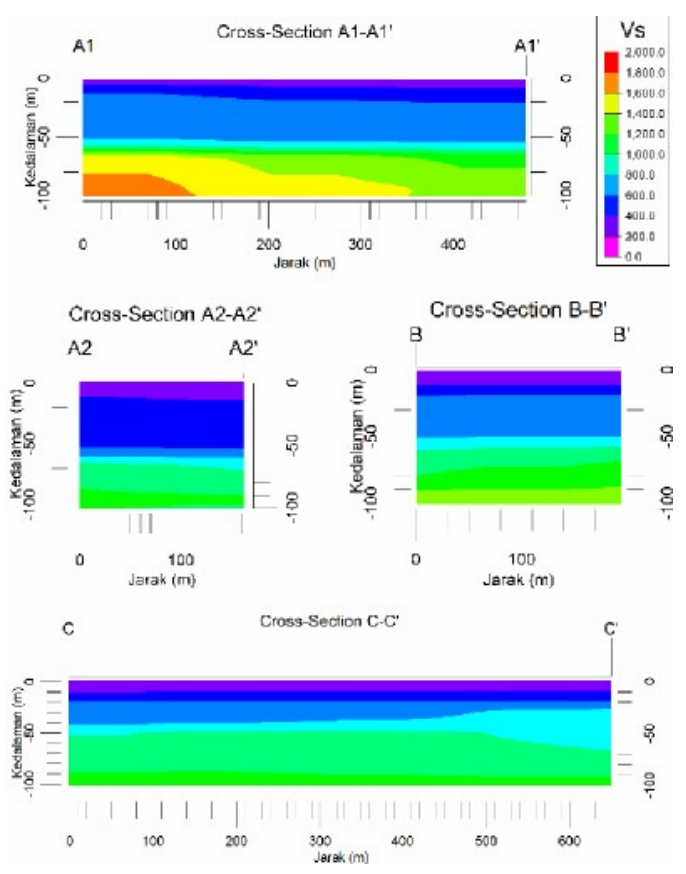

Gambar 3. Sayatan Pemodelan 3D

Berdasarkan sayatan pemodelan nilai $v_{\mathrm{s}}$, dapat diketahui bahwa ketebalan lapisan sedimen di titik A1 adalah $50 \mathrm{~m}$, di titik A2 adalah $15 \mathrm{~m}$, di titik A3 adalah $25 \mathrm{~m}$ serta untuk daerah longsor bagian B adalah $20 \mathrm{~m}$. Lapisan sedimen pada daerah tersebut ditunjukkan oleh spektrum warna ungu tua dan biru tua yang diketahui sebagai tanah keras berupa batuan pasir atau batuan lempung pada Formasi Andesit. Untuk ketebalan lapisan sedimen di daerah longsor bagian $\mathrm{C}$ adalah sekitar $20 \mathrm{~m}$ yang juga ditunjukkan oleh spektrum warna ungu tua dan biru tua yang diketahui sebagai tanah sedang dan keras berupa lempung, tuf, dan batuan lempung pada Formasi Kebobutak.

\section{Faktor Amplifikasi}
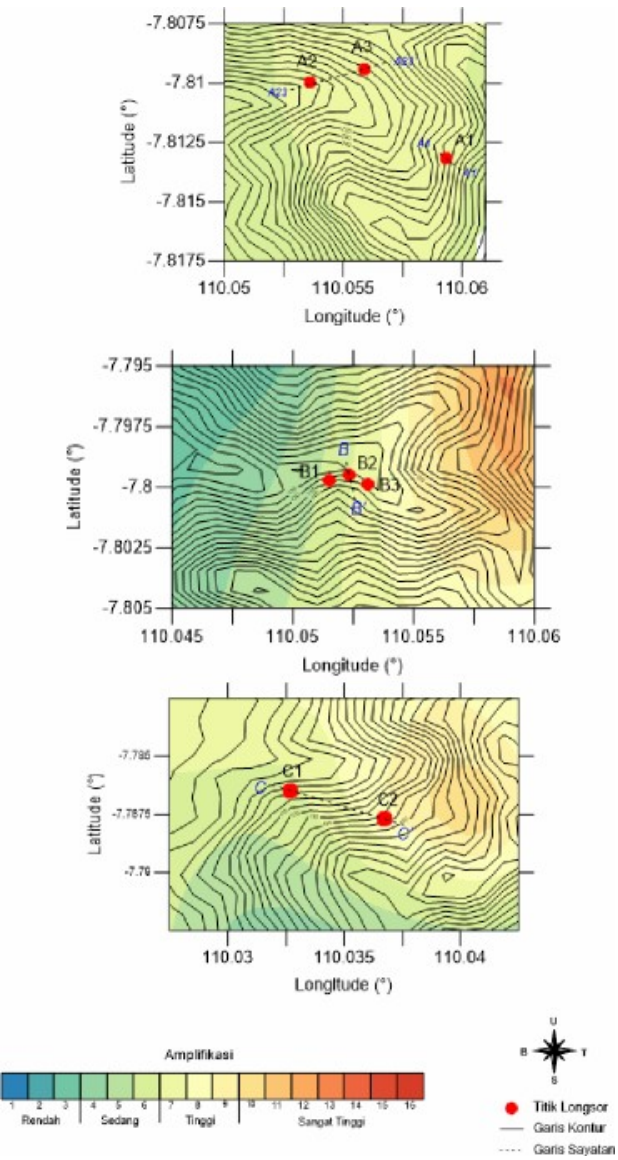

Gambar 4. Mikrozonasi Faktor Amplifikasi

Berdasarkan hasil mikrozonasi pada Gambar 3, maka dapat diketahui bahwa faktor amplifikasi di Kecamatan Bagelen berada dalam kategori sedang dan tinggi, yaitu bernilai 7 di daerah bagian A, bernilai 6 dan 7 di daerah bagian B, serta bernilai 6 dan 8 di daerah bagian $\mathrm{C}$.

Amplifikasi gelombang seismik dicirikan oleh adanya batuan sedimen yang berada di atas bedrock dengan kerapatan yang berbeda. Daerah yang permukaannya tersusun atas sedimen lunak (gambut, pasir, pasir lanau) dengan dasar yang keras memiliki nilai faktor 
amplifikasi yang tinggi. Semakin besar perbandingan kontras impedansi antara kedua lapisan tersebut maka nilai faktor amplifikasinya juga semakin tinggi. Faktor amplifikasi bisa bertambah jika batuan telah mengalami deformasi (pelapukan, pelipatan, dan pesesaran) yang mengubah sifat batuan.
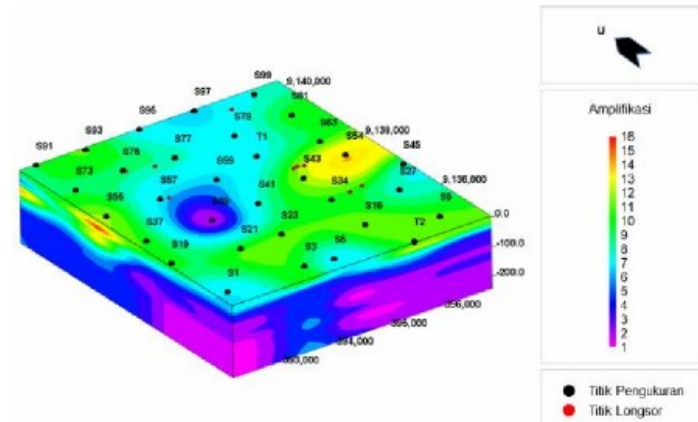

Gambar 5. Pemodelan 3D Nilai Amplifikasi

Kurva $\mathrm{H} / \mathrm{V}$ yang mengandung nilai amplifikasi dapat diubah menjadi kurva amplifikasi terhadap kedalaman. Nilainilai pada kurva yang telah diubah tersebut kemudian dimodelkan secara 3D untuk diperoleh pemodelan amplifikasi. Pemodelan tersebut, Gambar 5, dapat menunjukkan perbedaan karakteristik geologi antara lapisan sedimen dan lapisan bedrock. Berdasarkan pemodelan tersebut dapat diketahuin bahwa titik-titik longsor berada pada lapisan permukaan yang memiliki nilai amplifikasi tinggi, yaitu ditunjukkan oleh spektrum warna hijau. Hal ini menunjukkan adanya perbedaan karakteristik geologi yang signifikan antara lapisan sedimen dan lapisan bedrock.
Daerah longsor bagian A, B, maupun $\mathrm{C}$ merupakan wilayah dengan kemiringan lereng curam dan banyak vegetasi yang tumbuh di sekitarnya. Kondisi ini mengakibatkan daerah tersebut mudah mengalami pelapukan. Pelapukan yang terjadi dapat menyebabkan karakteristik geologi tanah berubah menjadi lebih halus ataudensitasnya menjadi berkurang sehingga faktor amplifikasi membesar.

\section{Indeks Kerentanan Seismik}

Indeks kerentanan seismik menyatakan kemampuan lapisan permukaan tanah menahan deformasi. Nilai indeks kerentanan seismik menunjukkan kestabilan struktur tanah, dimana semakin tinggi nilai indeks kerentanan seismik maka tingkat kestabilan struktur tanah semakin kecil.
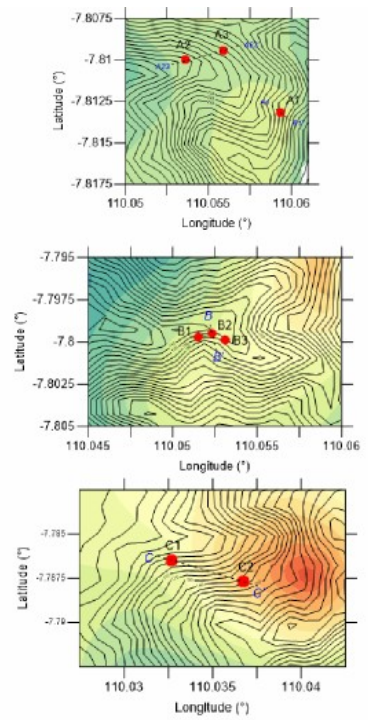

Indeks Kerentanan Seismik (s $\%$ m)
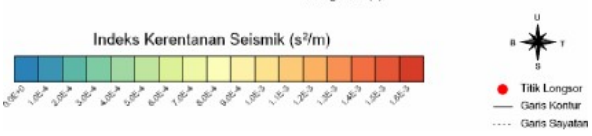

Gambar 6. Mikrozonasi Indeks Kerentanan Seismik 
Berdasarkan hasil mikrozonasi pada Gambar 6, maka dapat diketahui bahwa daerah longsor bagian A memiliki nilai $K g 5 \times 10^{-4} \mathrm{~s}^{2} / \mathrm{m}$ hingga $6 \times 10^{-4} \mathrm{~s}^{2} / \mathrm{m}$ dan daerah longsor bagian $B$ memiliki nilai Kg $6 \times 10^{-4} \mathrm{~s}^{2} / \mathrm{m}$ hingga $7 \times 10^{-4} \mathrm{~s}^{2} /$ m. Kedua nilai tersebut berada dalam kategori sedang, sedangkan pada daerah longsor bagian $\mathrm{C}$ berada pada kategori sedang dan tinggi dengan nilai $6 \times 10^{-4} \mathrm{~s}^{2} / \mathrm{m}$ dan $1,1 \times 10^{-3}$ $\mathrm{s}^{2} / \mathrm{m}$.

Kondisi permukaan suatu tebing yang telah mengalami pelapukan mengubah material kompak menjadi material lepas seperti batuan pasir, batuan lempung, atau tuff. Karakter material tersbut di musim penghujan adalah memiliki kemampuan menyerap air dan berpotensi mengalami gerakan di atas bidang gelincir. Air yang terserap tersebut mendorong material yang berada di lereng untuk bergerak turun karena massa material bertambah. Apabila kondisi tebing sangat curam, maka kemampuan tebing tersebut untuk menahan material yang runtuh semakin berkurang dan material berat tersebut semakin mudah untuk turun atau mengalami longsor.

\section{Simpulan}

Daerah longsor di Kecamatan Bagelen berada pada persebaran nilai frekuensi predominan $6-8$ $\mathrm{Hz}$, nilai faktor amplifikasi $6-8$, nilai ketebalan sedimen $15-50 \mathrm{~m}$, dan nilai indeks kerentanan seismik $5 \times 10-4-1,1 \times 10-3 \mathrm{~s} 2 / \mathrm{m}$. Daerah tersebut didominasi oleh batuan keras breksi-andesit, batuan lempung dan batuan pasir, dengan kemiringan curam serta berada pada topografi tinggi yang menyebabkan proses pelapukan terjadi lebih cepat dan mempermudah material lapuk untuk terlongsorkan.

\section{Referensi}

1. Dewi, Tara Shinta. (2017). Zonasi Rawan Bencana Tanah Longsor dengan Metode Analisis GIS: Studi Kasus Daerah Semono dan Sekitarnya, Kecamatan Bagelen, Kabupaten Purworejo, Jawa Tengah. Jurnal Mineral, Energi dan Lingkungan Vol. 1 ISSN 2549-7197.

2. BPS Kabupaten Purworejo. (2016). Kecamatan Bagel en dalam Angka: 2017. Purworejo: BPS Kabupaten Purworejo.

3. Atmoko, Dadang Tri. (2017). Analisis Bahaya Longsorlahan di Wilayah Kecamatan Bagelen, Kab. Purworejo, Provinsi Jawa Tengah. Tesis. Yogyakarta: UGM 
4. Mey, Estuning Tyas Wulan. (2009). Land Use Planning for Settlements Area in consideration of Flood and Landslide Hazards in Bagelen, Purworejo, Indonesia. Indonesian Journal of Geography ISSN 00249521 Vol.41. Gadjah Mada University.

5. Warnana, Dwa Desa, Ria Asih Aryani Soemitro \& Widya Utama. (2011). Local Site Effect of a Landslide in Jember based on Microtremor Measurement. The Second International Conference on Earthquake Engineering and Disaster Mitigation (ICEEDM-2) Surabaya 19-20 July 2011.

6. Shaleha, Ayu, Supriyadi \& Ngurah Made Darma Putra. (2016). Identifikasi Struktur Lapisan Tanah Daerah Rawan Longsor di Kecamatan Banyubiru, Kabupaten Semarang dengan Metode HVSR. Unnes Physics Journal 5 (2) 2016.

7. Ramadhan, Faiz Deja. (2016). Analisis Data Mikroseismik untuk Pemetaan Area Rawan Longsor di Daerah Dieng Kulon, Desa Karangtengah, Kecamatan Batur, Kabupaten Banjarnegara, Jawa Tengah. Skripsi. Yogyakarta:

Universitas Gadjah Mada.
8. Badan Standarisasi Nasional. (2012). Tata Cara Perencanaan Ketahanan Gempa dan Struktur Bangunan Gedung dan Non Gedung. Jakarta: BSN, SNI 1726: 2012. 